\title{
A Pilot Community-Based Study on Association of Khat (Catha edulis) Chewing Practice with Psychosis in Yemen
}

\author{
Abdullatif Daiffallah Ali ${ }^{1, ~ *, ~ A b d u l e l a h ~ H u s s i e n ~ A l-A d h r o e y ~}{ }^{2}$, Abdulqawi Ali Al-Shammakh ${ }^{1}$ \\ Amat Al-Khaleq Obad Mehrass ${ }^{3}$, Hamoud Yahya Jaber ${ }^{4}$, Hadi Mohammed Mujlli ${ }^{5}$ \\ ${ }^{1}$ Department of Biochemistry, Faculty of Medicine and Health Sciences, Thamar University, Dhamar, Yemen \\ ${ }^{2}$ Department of Medical Basic Sciences, Faculty of Medicine and Health Sciences, Thamar University, Dhamar, Yemen \\ ${ }^{3}$ Department of Gynaecology and Obstetrics, Faculty of Medicine and Health Sciences, Thamar University, Dhamar, Yemen \\ ${ }^{4}$ Department of Community Medicine, Faculty of Medicine and Health Sciences, Thamar University, Dhamar, Yemen \\ ${ }^{5}$ Department of Neurology, Faculty of Medicine and Health Sciences, Thamar University, Dhamar, Yemen
}

\begin{abstract}
Email address:
abdullatifwhite@gmail.com (A. D. Ali),husssien75@gmail.com (A. H. Al-Adhroey), aqawi54@gmail.com (A. A. Al-Shammakh), amatmehrass@gmail.com (A. A. O. Mehrass),hamoudjaber@yahoo.com (H. Y. Jaber), dr.hadimujlli @gmail.com (H. M. Mujlli)
\end{abstract}

\section{To cite this article:}

Abdullatif Daiffallah Ali, Abdulelah Hussien Al-Adhroey, Abdulqawi Ali Al-Shammakh, Amat Al-Khaleq Obad Mehrass, Hamoud Yahya Jaber, Hadi Mohammed Mujlli. A Pilot Community-Based Study on Association of Khat (Catha edulis) Chewing Practice with Psychosis in Yemen. American Journal of Health Research. Vol. 3, No. 2, 2015, pp. 91-96. doi: 10.11648/j.ajhr.20150302.16

\begin{abstract}
Community-based studies on association of khat (Catha edulis) chewing practice with psychological problems among the ethnic users in Yemen have been strongly recommended. The present study was aimed to investigate the association of this practice with stress, sleep disturbances, and anorexia in Dhamar area which is a major source of khat in Arabian Peninsula. A cross-sectional study with a pre-tested questionnaire was carried out among 148 khat users and 150 non-users of khat. The psychological health outcomes (stress, sleep disturbances, and anorexia) were measured by self-assessment method. The estimated risks to predict the probability that participants would develop stress, sleep disturbances, and anorexia according to their khat chewing were examined using the Poisson regression model incorporating the robust estimator. Association of sleep disturbances and anorexia with stress weas also evaluated. The findings of the present study showed that stress, sleep disturbances, and anorexia were found to be increased significantly $(P<0.001)$ by $8.97,9.28$, and 7.28 times among the khat users, respectively. Accordingly, sleep disturbances and anorexia were significantly associated with stress ( $\mathrm{PR}=3.03 ; P<0.001$, $\mathrm{PR}=2.33 ; P<0.001$, respectively). The results of this survey increase the need for attention among the regarded professionals about this harmful habit that can defect present and future of Yemeni people dramatically. However, more longitudinal researches pertaining to the contributory causal relationship of khat with psychosis are particularly needed.
\end{abstract}

Keywords: Khat Chewing Practice, Psychosis, Stress, Sleep Disturbances, Anorexia, Yemen

\section{Introduction}

Currently, Yemeni people are living in a severe poverty, food insecurity, political instability, and civil conflicts. Khat or qat (Catha edulis plant) chewing is a public psychostimulant-based practice that affects all aspects of Yemeni life with its harmful healthy, economic, and social consequences [1]. The ethnopharmacological standing of this plant was originated many centuries ago and essentially related to its physical and psycho-stimulant effects [2]. The soft young fresh leaves are chewed for at least three hours per day [3].This evergreen shrub is commonly cultivated in particular districts of Yemen and East Africa [1]. Previously, this habit was restricted between the rural communities residing the high altitudes areas where khat is originally grown [4]. Recently, as the transportation and communication means have been developed, thus khat practice becomes a major societal habit all over the country [5]. The use of khat has been spreading to the Israel, USA, and Western Europe where Yemeni and East Africa people have arrived [6]. The reported data about the prevalence of this habit in Yemen give an indication that at least $90 \%$ of men are khat users [7, 8]. Along with prevalent of this habit, almost among all Yemeni families, a lot of the literature confirms its negative impacts on the users, their families, and society [3]; for a review see [9, 1]. In 1973, the WHO Expert 
Committee on Drug Dependence has listed khat and recommended studying its psychoactive substances [10]. A psychoactive cathinone, structurally and functionally similar to D-amphetamine, was isolated from C. edulis [11]. Numerous studies on the topic of khat induced psychotic and schizophrenia-type disorders were systematically reviewed $[12,13,9]$; the majority of the related studies were case reports which could not reflect the risk factors of psychosis based on the population. Hence, the present study aims at evaluation of its association with stress, sleep disturbances, and anorexia among Yemeni people who are suffering chronic social and economic stressors.

\section{Methodology}

\subsection{Study Area and Study Population}

The present community-based cross-sectional study was conducted in Dhamar governorate located 100 kilometers southward of Sana'a, the capital city of Yemen. Dhamar governorate is organized into 12 districts which became catchment centers for the Dhamar General Hospital. Dhamar falls between latitude $14^{\circ} 32^{\prime} 33^{\prime \prime} \mathrm{N}$ and longitude $44^{\circ} 24^{\prime} 18^{\prime \prime} \mathrm{E}$. This area has a cold climate in winter and moderate in summer with temperature and altitude ranging between below 0 to 28 Celsius and 760 to 2848 meters above sea level. Agriculture is the main economic activity of the population with khat plantation occupying the majority of the total farmland.

The absolute precision of this study was designed at $\pm 8 \%$ with 95\% confidence level for two strata of the study population, khat users (KU) and khat non-users (KNU). The subjects of this study include the apparently healthy patients' companions who visited the hospital between December 2013 and June 2014. Two hundred ninety eight participants (KU = 148 and $\mathrm{KNU}=150$ ) aged $20-75$ years were successfully enrolled. The protocol of this study has been approved by the Faculty of Medicine and Health Sciences, Thamar University, Yemen. During the visits to the hospital, informative meetings were held with the subjects for providing a clear description of the study's aims. The participants were informed that their involvement is completely voluntary. All the study subjects were consented to participate in the study.

\subsection{Questionnaire Survey}

The data were collected using a pre-tested questionnaire constructed in Arabic, the native language. All participants were interviewed by local trained medical staffs from the Faculty of Medicine and Health Sciences_to fill up the questionnaire. The operational descriptions of the study variables, viz. stress, sleep disturbances, anorexia, khat user, and khat non-user were as the following: worries about the financial situation and responsibilities to family; problems in sleep beginning and maintaining; day or night low appetite; a chronic user who had habitually used khat for more than two years; and a person who had rarely or never used khat, respectively.

\subsection{Psychological Study}

The psychological health outcomes (stress, sleep disturbances, and anorexia) were measured by self-assessment method [14]. Because the study population is living a civil conflict, and acute socio-economic stressors, the tendency to respond to the questions with an irritated behavior was highly suspected. Hence, for controlling the extreme responding (ER) bias, a dichotomous format was performed [15]. After all, a "Yes" response indicated "often" and "No" response indicated "not often." Association of potential risk with the health outcomes was assessed. As well, the risk of stress on sleep disturbances, and anorexia was also evaluated.

\subsection{Data Analysis}

Data were processed and dichotomously analyzed using IBM SPSS version 22.0 statistical software. For the purpose of statistical analysis, the participants' variables were evaluated as the following: stress, sleep disturbances, and anorexia as dependent variables; and age, gender, education, and khat practice as the potential risk factors. Univariate analysis was developed to assess the association of the potential risk factors with the dependent variables. Variables that associated with the dependent variables at a $P$ value of $\leq 0.20$ were used to adjust the multivariate regression model $[16,17]$. Association of stress with sleep disturbances and anorexia was also examined. With regards to recommendations of the recent statistical literature concerning the regression models that are most practical for the cross-sectional studies of dichotomous outcomes, the Poisson regression model incorporating the robust estimator was used [18, 19]. The prevalence risk (PR) and corresponded estimated risk $(\mathrm{ER}=\mathrm{PR}-1)$ for predicting stress, sleep disturbances, and anorexia among the study population by their age, gender, education and khat practice were then developed. $P \leq 0.05$ was considered statistically significant.

\section{Results}

\subsection{Demographic Characteristics of Participants}

Table 1 shows the general characteristics of the study population. The majority of the participants $(83.9 \%)$ were $20-$ 45 years old. More than two-thirds of the participants were males $(73.2 \%)$ and $17.8 \%$ illiterate. Overall, $21.8 \%, 27.9 \%$, and $31.5 \%$ of the subjects experienced stress, sleep disturbances, and anorexia. However, the prevalence of stress, sleep disturbances, and anorexia was noticeably higher among khat users than among khat non-user (39.9\% vs. $4.0 \%$, $51.4 \%$ vs. $4.7 \%, 56.8 \%$ vs. $6.7 \%$, respectively).

\subsection{Association of Potential Risk Factors with Health Outcomes}

Univariate analysis to predict the probability that participants would develop stress, sleep disturbances, and anorexia according to their age, gender, education, and khat practice is shown in Table 2. The results confirmed that khat 
practice as a discrete predictor for stress, is noticeable however, sleep disturbances and anorexia were confounded by gender and education of the participants. The estimated risk of stress was significantly increased 8.97 times $(\mathrm{PR}=$ 9.97; $95 \% \mathrm{CI}=4.44,22.37 ; P<0.001)$ by khat chewing. However, the risk on sleep disturbances was significantly 0.66 times larger among the gender male than female $(\mathrm{PR}=$ $1.664 ; 95 \% \mathrm{CI}=1.01,2.73 ; P=0.045), 0.77$ times larger among the uneducated group $(\mathrm{PR}=1.77 ; 95 \% \mathrm{CI}=1.21,2.59$; $P=0.003)$ and 10 times larger among the khat users (PR $=$ $11.00 ; 95 \% \mathrm{CI}=5.25,23.07 ; P<0.001)$. Similarly, anorexia was significantly increased 0.66 times $(\mathrm{PR}=1.66 ; 95 \% \mathrm{CI}=$
$1.05,2.63 ; P=0.030)$ among the male gender group, 7.51 times $(\mathrm{PR}=8.51 ; 95 \% \mathrm{CI}=4.60,15.75 ; P<0.001)$ among the khat users group. During the univariate analysis, the khat practice was confirmed to be significantly associated with stress among the study subjects in Dhamar area; age, gender, and education showed levels of significant of more than 0.20 . However, associations of khat practice with sleep disturbances and anorexia were confused with age, gender, and education of the study subjects which were significantly associated with the study's health outcomes. Therefore, the independency of khat practice was assessed by developing multivariate regression model adjusted with these confounders.

Table 1. General characteristics of the study population participated in the study ( $n=298)$

\begin{tabular}{|c|c|c|c|}
\hline \multirow{2}{*}{ Variables } & \multirow{2}{*}{ All subjects n (\%) } & \multicolumn{2}{|c|}{ The study groups n (\%) } \\
\hline & & KU $(n=148)$ & NKU (n=150) \\
\hline \multicolumn{4}{|l|}{ Age groups } \\
\hline $20-45$ years & $250(83.9)$ & $128(86.5)$ & $122(81.3)$ \\
\hline $46-70$ years & $48(16.1)$ & $20(13.5)$ & $28(18.7)$ \\
\hline \multicolumn{4}{|l|}{ Gender } \\
\hline Male & $218(73.2)$ & $117(79.1)$ & $101(67.3)$ \\
\hline Female & $80(26.8)$ & $31(20.9)$ & $49(32.7)$ \\
\hline \multicolumn{4}{|l|}{ Education } \\
\hline Read \& write & $245(82.2)$ & $114(77.0)$ & $131(87.3)$ \\
\hline illiterate & $53(17.8)$ & $34(23.0)$ & $19(12.7)$ \\
\hline \multicolumn{4}{|l|}{ Stress } \\
\hline Yes & $65(21.8)$ & $59(39.9)$ & $6(4.0)$ \\
\hline No & $233(78.2)$ & $89(60.1)$ & $144(96.0)$ \\
\hline \multicolumn{4}{|c|}{ Sleep disturbances } \\
\hline Yes & $83(27.9)$ & $76(51.4)$ & $7(4.7)$ \\
\hline No & $215(72.1)$ & $72(48.6)$ & $143(95.3)$ \\
\hline \multicolumn{4}{|l|}{ Anorexia } \\
\hline Yes & $94(31.5)$ & $84(56.8)$ & $10(6.7)$ \\
\hline No & $204(68.5)$ & $64(43.2)$ & $140(93.3)$ \\
\hline
\end{tabular}

Table 2. Univariate analysis for the potential risk factors of stress, sleep disturbances, and anorexia among the study population in Dhamar, Yemen ( $n=298$ )

\begin{tabular}{|c|c|c|c|c|}
\hline Model & Variable categories & Prevalence \% & PR $(95 \%$ CI $)$ & $P$ \\
\hline \multicolumn{5}{|l|}{ Stress } \\
\hline Age & $20-45$ vs. $46-70$ & 21.2 vs. 25.0 & $1.18(0.68,2.03)$ & 0.553 \\
\hline Gender & Male vs. female & 22.5 vs. 20.0 & $1.12(0.68,1.86)$ & 0.649 \\
\hline Education & Read \& write vs. illiterate & 22.4 vs. 18.9 & $0.84(0.46,1.54)$ & 0.573 \\
\hline Khat practice & Khat user vs. non-user & 39.9 vs. 4.0 & $9.97(4.44,22.37)$ & $<0.001^{*}$ \\
\hline \multicolumn{5}{|c|}{ Sleep disturbances } \\
\hline Gender & Male vs. female & 31.2 vs. 18.8 & $1.66(1.01,2.73)$ & $0.045^{*}$ \\
\hline Education & Read \& write vs. illiterate & 24.5 vs. 43.4 & $1.77(1.21,2.59)$ & $0.003 *$ \\
\hline Khat practice & Khat user vs. non-user & 51.4 vs. 4.7 & $11.00(5.25,23.07)$ & $<0.001 *$ \\
\hline \multicolumn{5}{|l|}{ Anorexia } \\
\hline Age & $20-45$ vs. $46-70$ & 31.2 vs. 33.3 & $1.07(0.69,1.66)$ & 0.768 \\
\hline Gender & Male vs. female & 35.3 vs. 21.3 & $1.66(1.05,2.63)$ & $0.030 *$ \\
\hline Khat practice & Khat user vs. non-user & 56.8 vs. 6.7 & $8.51(4.60,15.75)$ & $<0.001^{*}$ \\
\hline
\end{tabular}

PR: prevalence risk; CI: confidence interval

* Significant association $(P \leq 0.05)$

As shown in Table 3, the multivariate regression model reveals the participant's gender as an insignificant predictor for sleep disturbances $(\mathrm{PR}=1.34 ; 95 \% \mathrm{CI}=0.88,2.06 ; P=$ $0.176)$ and anorexia $(\mathrm{PR}=1.29 ; 95 \% \mathrm{CI}=0.87,1.92 ; P=$
0.199). Educational level of the participants, however confounded the relationship between khat chewing and sleeps disturbances; significantly increased 0.41 times with the illiterate $(\mathrm{PR}=1.41 ; 95 \% \mathrm{CI}=1.02,1.93 ; P=0.035)$. 
Accordingly, the khat practice was considerably exhibited as a distinguished predictor for sleep disturbances and anorexia. These significant contributions continued after adjusting for the confounders, viz. gender, and educational level. The adjusted risks for predicting sleep disturbances and anorexia among the population were 9.28 times $(\mathrm{PR}=10.28 ; 95 \% \mathrm{CI}=$ $4.87,21.68 ; P<0.001)$ and 7.28 times $(\mathrm{PR}=8.28 ; 95 \% \mathrm{CI}=$ 4.46, 15.37; $P<0.001)$ higher among khat users, respectively.

\subsection{Association of Sleep Disturbances and Anorexia with Stress}

Regarding stress induces sleep disturbances and anorexia, the results of the present study confirmed stress as a significant predictor for disturbances and anorexia. Associations of the "No" versus "Yes" responses on sleep disturbances and anorexia against stress among the study population were $12.6 \%$ versus $45.8 \%$ and $13.7 \%$ versus $39.4 \%$, respectively "Fig. 1". Participants who suffered from stress were considerably had higher frequencies of sleep disturbances and anorexia. The multivariate analysis for association of sleep disturbances and stress exhibited that sleep disturbances increases $2.03(\mathrm{PR}=3.03 ; 95 \% \mathrm{CI}=2.17$, $4.22 ; P<0.001)$ by stress. On the other hand, anorexia increases 1.33 times $(\mathrm{PR}=2.33 ; 95 \% \mathrm{CI}=1.71,3.17 ; P<$ 0.001). The study results confirmed that sleep disturbances and anorexia were associated with stress among the study population in Dhamar area.

Table 3. Multivariate analysis for the potential risk factors of stress, sleep disturbances and anorexia among the study population in Dhamar, Yemen ( $n=298$ )

\begin{tabular}{llll}
\hline Model & Adjusted PR & 95\% CI & P \\
\hline Stress $^{1}$ & & & \\
Khat practice & 9.97 & $4.44,22.37$ & \\
Sleep disturbances & & & \\
Gender & & $0.88,2.06$ & $0.001^{*}$ \\
Education & 1.34 & $1.02,1.93$ & 0.176 \\
Khat practice & 1.41 & $4.87,21.68$ & $0.035^{*}$ \\
Anorexia & 10.28 & & $<0.001^{*}$ \\
Gender & & $0.87,1.92$ & 0.199 \\
Khat practice & 1.29 & $4.46,15.37$ & $<0.001^{*}$ \\
\hline
\end{tabular}

PR: prevalence risk; CI: confidence interval

1 As estimated by Univariate analysis

2 Adjusted with gender and education

3 Adjusted with gender

* Significant association $(P \leq 0.05)$

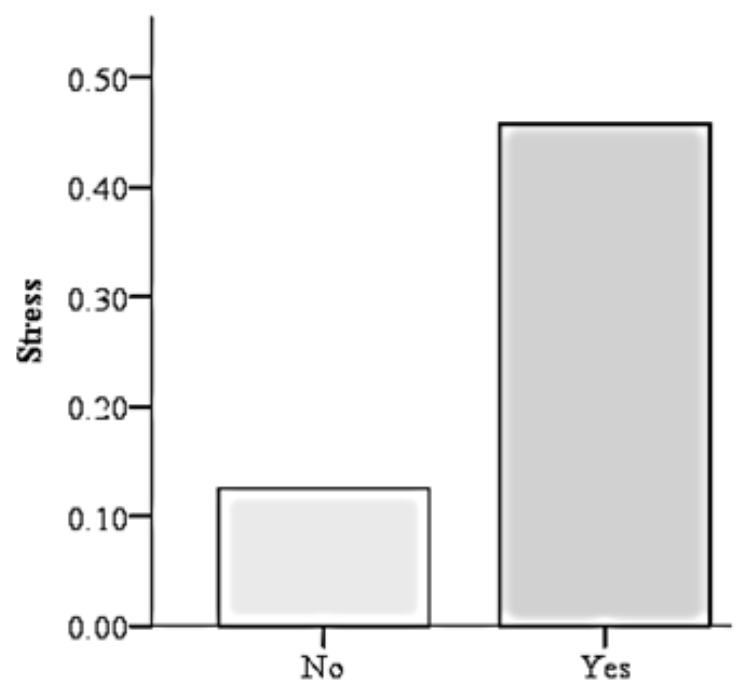

Sleep disturbances

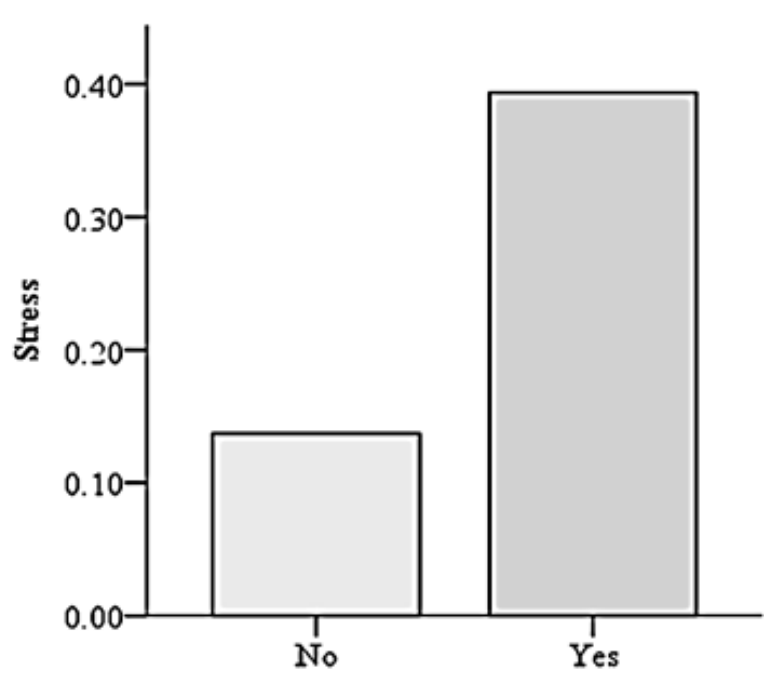

Anorexia

Figure 1. Regression plots of sleep disturbances and anorexia with stress among the study population in Dhamar, Yemen (n = 298); the adjusted prevalence risk for sleep disturbances and anorexia were $3.03(P<0.001)$ and $2.33(P<0.001)$, respectively

\section{Discussion}

Khat chewing practice is a deep-rooted ethnic habit in Yemen. It remains the major public concern that harmfully affects the users, their families, and community. The present study revealed that about one-third of the study population had suffered stress, sleep disturbances, and anorexia. The estimated risks for predicting these health outcomes alarmingly increased seven to nine times among khat users. Accordingly, sleep disturbances and anorexia were 
significantly associated with stress.

Many reports consider the relationship between khat and irritability, sleep problems, lethargy, depression and tiredness, interactions with social and environmental stressors, posttraumatic stress, and higher ratings of dependence [20-24]. There are significant evidences with regard to tensions produced by men spending their limited income on khat, end in family adversities $[25,26]$.

Khat leaves contain cathinone, a psychoactive alkaloid, which is structurally and functionally similar to D-amphetamine [11]. As confirmed by animal studies, behavioral responses and sensitization animal models for stimulant-induced psychosis revealed that a single administration of cathinone showed a dose-dependent locomotor activity and khat extract have related effects as amphetamines [27-29]. Cathinone increases the activity of dopaminergic pathways by inducing catecholamines, particularly dopamine, from central dopaminergic nerve terminals [5]. If psychotic disorders include instabilities in the dopamine neurotransmitter systems with which the catecholamine system may interact, then the contributory causal relationship of khat with psychosis may be biologically plausible [30].

Stress, sleep disturbance, and anorexia were found to be more strongly associated with khat chewing. The observed high levels of worries combined with sleep disturbances and eating disorders among the khat users possibly will increase their vulnerability to develop a chronic psychological stress which in turn triggers the development of psychosis [14, 31]. Hypothetically, if the vulnerability to psychosis is acquired as a result of a combination of biological factors in the early development and symptoms are developed in reaction to substance use or social stresses, therefore khat chewing has various ways to be a contributory cause of psychosis among the users in Yemen. The exposure to the psychoactive substances of khat during the early development possibly would increase the vulnerability of individual to psychosis $[12$ 32]. With time, the continued exposure plausibly can trigger the commencement of psychotic disorders in the vulnerable individuals (12); who are suffering from severe social and economic adversities, civil conflict, and a global terrorism.

\section{Conclusions}

It is reliable to emphasize that khat chewing practice is a significant risk factor for stress, sleep disturbances, and anorexia among the chronic khat users in Yemen. A contributory causal relationship between khat and psychosis is possible. Accordingly, the current distracting situation in Yemen (historically known as Happy Yemen) would increase the development of psychotic disorders among the chronic khat users. In Yemen, this deep-rooted habit needs a profound support of the concerned organizations in a way to control its medical, economic, and social consequences. Introduction of educational programs about the negative impacts of khat practice is imperative. However, more advanced biological and longitudinal population-based researches on its possibly related cause of psychosis are remarkably needed.

\section{Acknowledgments}

The financial support of the Faculty of Medicine and Health Sciences, Thamar University is gratefully acknowledged. The authors would like to thank Mr. Z. Al-Hetary, A. Al-Kholidy, S. Mogahed, M. Al-Mousheki, A. Ali, A. Al-Deen, M. Al-Edresi, A. Al-Shawki, M. Al-Shawki, M. Taher, A. Al-Somi, M. Al-Said, R. Al-Kohly, Y. Zoheir, and M. Al-Mass, from the Department of Medical Laboratories Sciences Thamar University for their generous help in the collection of the study data. The authors would like to acknowledge the Dhamar General Hospital staffs, for their kind support during this survey. We also thankfully appreciate the study population for their participation in this study.

\section{References}

[1] N. A. Hassan, A. A. Gunaid and I. M. Murray-Lyon, "Khat (Catha edulis): Health aspects of khat chewing," East Mediterranean Health Journal, vol. 13, p. 706-718, 2007.

[2] S. Weir, Qat in Yemen-Consumption and Social. Changes, London: British Museum Publication, 1985.

[3] WHO, "Report of the WHO intercountry meeting on the health, social and economic aspects of khat," Mogadishu, Geneva: World Health Organization, 1983.

[4] G. Cox and H. Rampes, "Adverse effects of khat: a review," Advances in Psychiatric Treatment, vol. 9, pp. 456-463, 2003.

[5] A. Al-Motarreb, M. Al-Habori and K. J. Broadley, "Khat chewing, cardiovascular diseases and other internal medical problems: The current situation and directions for future research," Journal of Ethnopharmacology, vol. 132, p. 540-548, 2010.

[6] N. Numan, " The Green Leaf: Khat," World Journal of Medical Sciences, vol. 7, pp. 210-223, 2012.

[7] N. Numan, "Exploration of adverse psychological symptoms in Yemeni khat users by the Symptoms Checklist-90 (SCL-90)," Addiction, vol. 99, pp. 61-65, 2004.

[8] A. K. Laswar and A. K. Darwish, "Prevalence of cigarette smoking and khat chewing among Aden University medical students and their relationship to BP and body mass index," Saudi Journal of Kidney Disease and Transplantation, vol. 20, pp. 862-866, 2009.

[9] S. Thomas and T. Williams, "Khat (Catha edulis): A systematic review of evidence and literature pertaining to its harms to UK users and society," Drug Science, Policy and Law, vol. 1, DOI: 10.1177/2050324513498332, 201.

[10] Szendrei, K. (1980). The chemistry of khat. Bulletin of Narcotics, 32, pp. 5-36.

[11] P. Kalix, "Catha edulis, a plant that has amphetamine effects," Pharmacy World \& Science, vol. 18, pp. 69-73, 1996.

[12] M. Odenwald, "Chronic khat use and psychotic disorders: A review of the literature and future prospects," Sucht, vol. 53, pp. 9-22, 2007. 
[13] N. Warfa, A. Klein, K. Bhui and G. Leavey, T. Craig, and S. Alfred, "Khat use and mental illness: A critical review," Social Science and Medicine, vol. 65, pp. 309-318, 2007.

[14] U. Hapke, U. Maske, C. Scheidt-Nave, L. Bode, R. Schlack, and M. Busch, ".Chronic stress among adults in Germany, Results of the German Health Interview and Examination Survey for Adults (DEGS1)," Bundesgesundheitsbl, pp. 749-754, 2013.

[15] D. L. Paulhus and S. Vazire, "The self-report method," in Handbook of research methods in personality psychology, New York: Guilford, 2007, pp. 224-239.

[16] R. B. Bendel and A. A. Afifi, "Comparison of stopping rules in forward regression," J Am Stat Assoc, vol. 72, pp. 46-53, 1977.

[17] R. H. H. Groenwold, O. H. Klungel, D. E. Grobbee and A. W. Hoes, "Selection of confounding variables should not be based on observed associations with exposure," Eur J Epidemiol, vol. 26, pp. 589-593, 2011

[18] J. Lee, C. S. Tan and K. S. Chia, "A Practical Guide for Multivariate Analysis of Dichotomous Outcomes," Annals Academy of Medicine, vol. 38, pp. 714-719, 2009.

[19] M. Coutinho, M. Scazufca and P. Menezes, "Methods for estimating prevalence ratios in cross sectional studies," Rev Saúde Pública, vol. 42, pp. 1-6, 2008.

[20] J. Fitzgerald, "Khat: A literature review," Khat: A literature review, $2009 . \quad$ [Online]. Available: http://www.ceh.org.au/downloads/Khat_report_FINAL.pdf. [Accessed September 2014].

[21] K. Bhui and N. Warfa, "Trauma, khat and common psychotic symptoms among Somali immigrants: a quantitative study," Journal of Ethnopharmacology, vol. 132, pp. 549-553, 2010.

[22] N. Warfa, K. Bhui, K. Phillip, K. Nandy and S. Griffiths, "Comparison of life events, substance misuse, service use and mental illness among African-Caribbean, black African and white British men in east London: a qualitative study," Diversity in Health and Social Care, vol. 3, pp. 111-121, 2006.

[23] K. Bhui, etal, "Traumatic events, migration characteristics and psychiatric symptoms among Somali refugees-Preliminary communication," Social Psychiatry and Psychiatric Epidemiology, vol. 38, pp. 35-43, 2003.

[24] M. Odenwald, etal, "Use of khat and posttraumatic stress disorder as risk factors for psychotic symptoms: a study of Somali combatants," Social Science and Medicine, vol. 69, pp. 1040-1048, 2009.

[25] Turning Point, "Khat Use in Somali, Ethiopian and Yemeni Communities in England: Issues and Solutions," London Home Office, 2004.

[26] S. L. Patel, S. Wright and A. Gammampila, "Khat use among Somalis in four English cities," 2005. [Online]. Available: http://collection.europarchive.org/tna/20080205132101/home office.gov.uk/rds/pdfs05/rdsolr4705.pdf [Accessed October 2014].

[27] D. J. Calcagnetti and M. D. Schechter, "Increase in the locomotor activity of rats after intracerebral administration of cathinone," Brain Research Bulletin, vol. 29, pp. 843-846, 1992.

[28] J. Zelger, H. Schorno and E. Carlini, "Behavioural effects of cathinone, an amine obtained from Catha edulis Forsk.: comparisons with amphetamine, norpseudoephedrine, apomorphine and nomifensine," Bulletin on Narcotics, vol. 32, p. $67-81,1980$.

[29] M. Banjaw, K. Miczek and W. Schmidt, "Repeated Catha edulis oral administration enhances the baseline aggressive behavior in isolated rats," Journal of Neural Transmisssion, vol. 113 , pp. 543-556, 2005.

[30] W. Hall and L. Degenhardt, "Cannabis use and the risk of developing a psychotic disorder," World Psychiatry, vol. 7, pp. 68-71, 2008.

[31] M. P. Fankhauser and K. C. Lee, "Eating disorders," in Applied Therapeutics: The clinical Use of Drugs, Baltimore: Lippincott Williams Wilkins, 2009.

[32] M. Sato, Y. Numachi and T. Hamamura, "Relapse of paranoid psychotic state in methamphetamine model of schizophrenia.," Schizophrenia Bulletin, vol. 18, pp. 115-122, 1992. 